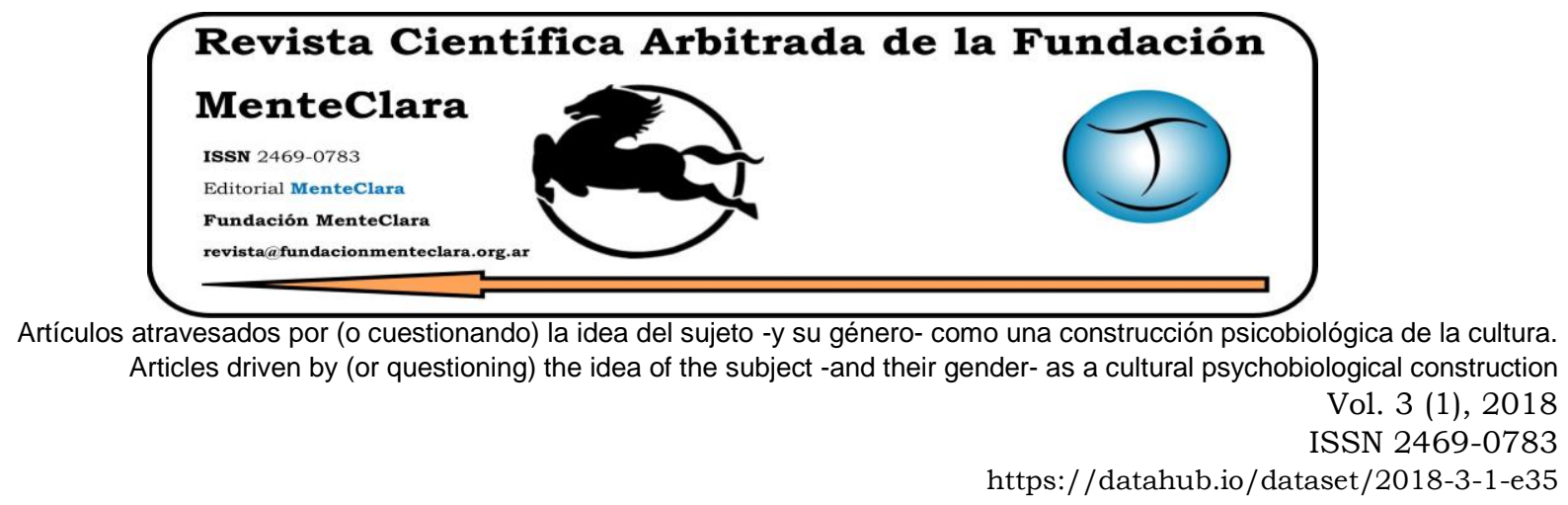

\title{
THE NATURE OF AWARENESS AS TANTRA: A PHENOMENOLOGY
}

\section{LA NATURALEZA DE LA CONCIENCIA COMO TANTRA: UNA FENOMENOLOGÍA}

Rudolph Bauer rbauer@rsbauer.net

Center for Consciousness Studies and Washington Center for Phenomenological and Existential Psychotherapy Studies.

Cómo citar este artículo / Citation: Bauer R. (2018). "The Nature of Awareness as Tantra: A Phenomenology". Revista Cientifica Arbitrada de la Fundación MenteClara, 3(1), 59-88. DOI: $10.32351 /$ rca.v3.1.38

Copyright: (C) 2018 RCAFMC. Este artículo de acceso abierto es distribuido bajo los términos de la licencia Creative Commons Attribution-Non Commercial (by-cn) Spain 3.0. Recibido: 07/02/2018. Aceptado: 08/03/2018 Publicación online: $30 / 04 / 2018$

Conflicto de intereses: Ninguno que declarar.

\begin{abstract}
This paper explores the phenomenology of awareness as the very nature of tantra. The paper also approaches phenomenologically the nature of tantric praxis. Through these phenomenologies there is the bringing forth a convergence of understanding about nature of awareness as tantra and tantra as the very nature of human awareness. Much of the emphasis within this paper is Tibetan Buddhism and most essentially the phenomenological Dzogchen lineage and traditions.
\end{abstract}

\section{Resumen}

Este artículo explora la fenomenología de la conciencia como la naturaleza misma del tantra. El documento también aborda fenomenológicamente la naturaleza de la praxis tántrica. A través de estas fenomenologías se produce una convergencia de entendimiento sobre la naturaleza de la conciencia como tantra y tantra como la 
naturaleza misma de la conciencia humana. Gran parte del énfasis en este documento es el budismo tibetano y, esencialmente, el linaje y las tradiciones fenomenológicas de Dzogchen.

\section{Palabras Claves/ Keywords}

Tantra; phenomenologyc, buddhism; dzogchen; tantric praxis; Tíbet; fenomenologia; budismo; práctica tántrica 


\section{Introduction}

Tantra is easily misunderstood and not easy to understand. The nature of Tantra is the continuity of awareness within our own self and continuity of awareness with others, continuity within the world and continuity within the cosmological universe. Tantra is the continuity of the experience of non- duality within duality. Tantra is the continuity of the experience within duality of non-duality.

\section{Oneness and Difference}

Tantra is the experience of oneness and difference simultaneously being held by us. Tantra is the experience of the continuity of the union of mind and awareness within our own self, within our own being. Tantra is the direct inside to inside extension of the field of awareness between our self and others. Tantra is true inter-subjectivity as within to within, inside to inside. Tantra is the directness of the experience of nonconceptual knowingness between us and all phenomena, between us and all appearance. Tantra is the connection and continuity between the light of our own awareness and the lucidity of phenomena. In the language of Jung, Tantra is the Mysterious Conjunctio.

Transmission

Tantra is a transmission beyond words and language. This transmission does not belong to any tradition. This transmission is the nature of human awareness, and this nature is the Buddha, or this nature is Shiva or this nature is the Christos. Buddha, Shiva, and Christos are archetypal metaphors of luminous awareness. Human awareness is the manifestation of primordial awareness as our very own subjectivity and as the manifestation of our mind and our embodiment.

Tantra is the experience of primordial timeless awareness manifesting in time. Tantra is us, holding simultaneously timeless awareness and 
time. Not to hold timeless awareness and time simultaneously creates a caricature of time and a caricature of human existence.

Some traditions value timeless awareness alone, foreclosing the actuality of time. Some traditions value time alone, foreclosing the actuality of timeless awareness. This existential splitting destroys the possibility of experiencing duality within non duality and non- duality within duality. One view devalues essence and the other view devalues appearance.

This luminous nature of awareness is our very own subjectivity, our very own personhood. Tantra is the capacity to extend this luminous awareness field into others and into the lucidity of all phenomena. Tantra is our openness, Tantra is our energy, Tantra is our light.

The Power of the Metabolization of Experience

Tantra is the power of the metabolization of experience. Awareness is not mere cognition but awareness is the power to digest and dissolve experience. Abinavagupta the 10th century Kashmir Shavite master would describe awareness as being the Fire of experiential digestion, a violent digestion. Through awareness experience is metabolized and becomes luminous energy. Through the power of awareness both positive and negative experience is dissolved within the embodied field of the light of awareness. The fire of Awareness extracts the luminous essence of all experience. This capacity of awareness to metabolize everything and anything is the foundational power of self-liberation.

Tantra Dissolves Dissociation

Tantra dissolves dissociation, both personal dissociation and cosmological dissociation. Tantra requires us entering into our awareness of awareness and our sustaining awareness and being sustained by awareness throughout the unfoldment of our life. Tantra 
brings forth the integration of mind and body within the light of awareness field. Tantra is the simultaneous embodiment of the dimension of our mind and the embodiment of the dimension of our body. Being in both our mind and in our embodiment, simultaneously unifies mind and body as personal non duality within duality.

Tantra brings forth the power of resonance, vast unbound resonance. Tantra is access to the life force both within our body and within our surrounding world and the vast cosmological universe. Tantra is resonance within the various dimensions of existence. These dimensions are Nirmanakaya, Sambogakaya and Dharmakaya. Nirmanakaya is the ordinary life of existence. Sambogakaya is archetypal dimension of existence, and Dharmakaya is pure potentiality of Being. Being which is not a being or thing in itself, rather Being which manifests Being in everything and anything as beings.

Tantra embodies the elemental-ness of phenomena and Tantra is the experience of all appearance as elemental-ness. Tantra embodies fire, earth, wind, space, and water within the world that we are. Tantra is spontaneous openness that gives us accessibility to the subtle dimensions of elemental-ness. Tantra is the transmission of elementalness. Tantra opens the alchemical doorway of experiencing the unfolding of elemental-ness and the infinite configurations of the elements. Tantra allows us to experience and relate to the elemental dimensions of our innermost experience of the vital-ness of life, the vital elemental-ness of phenomena.

Tantra brings forth the experience of soma. And Tantra brings forth the experience of psyche. Tantra brings forth the experience of the indivisibility of psyche and soma. Tantra is both physical and deeply beyond the physical, deeply subtle. Tantra is both gross and most subtle. Tantra requires the awakening of awareness. Tantra requires us to 
become aware of awareness within us and beyond us. Tantra requires us to experience all phenomena as primordial ground awareness manifesting itself as phenomena. Tantra is the experiencing of the manifestation of primordial awareness as everything and anything.

Tantra is the power of the extension of awareness, the power of amplification of awareness, the power of pacification of awareness and the power of the magnetization of awareness. Tantra is neither simplistic sexuality nor simplistic celibacy.

Tantra Integrates

Tantra integrates the masculine and feminine elements within human beings. Tantric experience is the invocation of the feminine dimension as gnosis, as jnana, as direct perception. Tantra brings forth the anima dimension within human love. Tantra brings forth the anima mystic foundation of human existence. Tantra embraces the feminine within us and the feminine surrounding us. Tantra liberates us through the grace of the feminine dimension.

Tantra is both sublimation of and the integration of our primal and primitive energies. These energies are both personal and cosmological. Tantra integrates both Eros and Thanatos. Tantra integrates the sexual instincts and survival instincts into the essential light of awareness, into the essential embodiment of awareness. Tantra integrates Thanatos and leads us into deathless awareness. Tantra allows to us to experience the appearing and disappearing of everything and anything. Tantra is pure self- manifestation of ground awareness.

The powerful instincts of humanness are not easy to integrate. The primitive instincts control much of human experience. When there is only ego functions, superego structures and the id or libidinal instinctive impulses there is constant conflict both within the person and within the 
person world configuration. Freud's magnificent work and understanding is the great western step to understanding Tantra. Without awareness, without the presence of the field of innate awareness, the ego, the instinctive id, and critical conscience of the superego configuration creates the realm of endless extremes. The person is both tormented by extremes of driven-ness and torments others by extremes of chaotic driven-ness of demandingness. These extremes are the extreme of abstinence and extremes of deprivation and the extremes of driven-ness and extremes of relentless discharge!

\section{Instinctiveness}

The sexual instinct is often located at one extreme, a sphere of extreme. As the dynamic sexual Eros instinct is repressed, foreclosed and dissociated from human experience, there is a gradual loss of vital-ness and a deep constriction of range of experience, the range of knowingness and the range cosmological relatedness. There is the eventful minimization and disappearance of Eros and vitality.

At the other sphere of extreme, is the person possessed by the sexual instinct and has no power of integration of the power of vital force of sexual instinctiveness. The person is integrated by and into the sphere of instinct alone. The person and their functions are taken into the sphere of instinct, controlled and subsumed by the instinctiveness. The person is possessed and completely preoccupied by the demands and the endless and ceaseless requirements of the instinct. Instinctiveness organizes everything and demands everything of the person and those around him or her. Instinct creates things and thingness of oneself and others. Everything is organized to gratify the driven-ness of the instinct. Instinct objectifies everyone and everything. Instinct objectifies the world. Instinct limits humanism to a mammalian dimensionality. Instincts cathect to cathartic expression alone and to discharging relentlessly and 
compulsively. Instinctiveness in its extreme invokes the vigilance of a predator.

Without the unfolding of sublimation, instinct becomes the central focus and central mechanism of the mind body continuum. Instinct becomes the singular mechanism to dissipate unbearable anxieties and unassimilated trauma. Instinct does not integrate but discharges painful and un-assimilated experience. Instinct becomes the anchor and base against foundational annihilation and deprivation anxiety as well as the primordial terror of ontological void-ness and lack. There is no awareness within the sphere of instinct itself. Instinct can foreclose the opening of awareness. Instinct concretizes thought and concretizes feelings and concretizes sensations and memory, and imagination. Instinct usurps self- regulation and usurps resonance into relentless discharge and fragmentation.

Most addictions are compulsions of instinct disturbance. Instinctiveness alone brings relentless agitation and discharge of the circular continuum of inter- resonance. Resonance is always temporary and self- comfort is temporary and fragmentary. Vigilance is the orientation of instinct. Instinctive discharge creates the illusionary sense of being rescued from deprivation and annihilation anxieties. This illusion is temporary and this illusion cannot sustain the continuous sense of awareness, the ongoing sense of continuity of being-ness.

\section{Philosophical Unreality}

Some eastern cultural traditions such as some forms of Buddhism and some forms of Hinduism traditions use their philosophical view of the unreality of the world, their view of the deluded-ness of experience as a way of avoiding deprivation and annihilation anxieties. Their view is that nothing is. Their view is profoundly dissociative in essence and actuality. 
Their philosophical view is a view of cosmological denial of the actuality of actuality. Cosmological denial and distortion! What then remains for them is the void of nihilism. What remains is the void-ness of meaning and void-ness of vitality. They consider this to be the meaning of emptiness.

For some of the cultural forms of Buddhism all life is suffering, all experience is impermanent, all desire is deluded, and a pervasive and meaningless causality dominates all experience until cessation by death. This is a most unhappy and depressive view of human existence. This is the view of spiritual materialism. This is the view of agnosia. This is the view of fatalism. This is a view of complete indifference and passionless life. This is not Tantra. This is not the effulgence of the embodiment of the experience of ongoing continuity of luminous awareness.

Kundalini

Kundalini is another word or language of Tantra. Kundalini is Tantra. In Tantra there is our unfolding inner expansion and embodiment of the light and the consequent embodiment of us by the light of awareness. So to enter Tantra we must relocate ourselves from being located in mind alone and move existentially into the drama of holding awareness, and becoming awareness, and living within the field of awareness of awareness, the field of embodied luminosity.

\section{Primitive Structures}

In this phenomenological reduction of becoming aware of awareness, the field of awareness opens infinite in its horizons, and is vast and multidimensional. Awareness itself brings forth this alchemical event. Awareness awakens of its own accord and its own time, and in its own way. Through the awakening of awareness the ego, superego and id instinctive configuration are slowly transformed into the embodied field 
of awareness. The ego, the superego and sphere of instinct are all integrated and metabolized by the light of awareness, the light of Tantra, the light of the kundalini, the light of resonance and the light of embodiment. The ego or mind is embodied into the sphere of light. The superego is assimilated and metabolized into the power of the light of awareness, and the sphere of instinctiveness is pulled into and metabolized by the light of awareness. The sphere of instinctiveness is opened and infused by non- conceptual knowingness and openness. The sphere of instinctiveness cracks open and is infused through the power of the light and the spaciousness of awareness. This is wonderful and amazing. This opening is the beginning of self- liberation.

The primitive structures of humanness are pulled into the fire of awareness, the unfolding of awareness. The primitive structures are embodied by awareness, infused by awareness and completed within awareness. The mind is embodied as is the instincts and as is the superego.

Thus there is the radical shift from self-regulation through discharge alone to regulation through resonance.

The embodiment of the instincts is of great importance as there is this shift from a discharge cycles into the cycle of resonance, vast ongoing resonance. This non-dual resonance dissolves the dissociative-ness of instinctiveness. The power and vitality of instinct now serves the human being by being infused by the light and the light infusing the instinct and opening the instinct unto awareness and the self-liberation from containment. The sphere of instinct opens into the self-manifestation of awareness. So instinct itself becomes integrated into the selfmanifestation of Eros, and by this ongoing and unfolding experience of luminosity and vital-ness the body of light is becoming formulated. This body of light is informed through our awareness of death and through 
integration of Thanatos within our luminous awareness. Now luminous deathless awareness becomes the medium beyond death.

\section{Elementals}

What is the great secret of Tantra? The secret of Tantra is that Tantra is naturally and non-conceptually the unfolding of the elementals within human experience. Awareness opens the elemental-ness and the aliveness of elemental-ness. The elemental-ness is activated and opened and no longer experientially foreclosed. The elemental dimension of experience is activated and the vital-ness of the alchemical process unfolds naturally and spontaneously.

There is the alchemical dimension of human experience. The elemental-ness is not simply philosophical ideation but experience of the subtle dimension of awareness permeating everything and anything. This is actually the give-ness of awareness resulting from the transmission of awakened awareness from one awakened person to another person. There is the awakening through energetic transfer of luminosity from one person to another. This can happen naturally and culturally. This can happens in families. How wonderful.

Awakened awareness awakens awareness. The energy of awaken awareness awakens the energy of awareness within our self and within others. Awakened awareness awakens the energy within the person and the place of the person. There are awakened persons, awakened families and awakened places. This is wonderful!

The role of sexuality within Tantra is present but not the sole focus of Tantra. Some think the focus of Tantra is the simplistic integration of sexuality and the intensity of sexuality into meditative life. Some think that sexual intensity is the instrument of Tantra, the essence of Tantra. This understanding is completely false. The instinctive sphere of energy 
as sexuality which is primitive opens into the unfoldment of refinement of luminous Eros. As this sphere of sexual energy unfolds within the experience of luminous awareness, the permeating luminosity of awareness is the alchemical instrument and alchemical substance metabolizing sexuality into the luminous light of embodied awareness.

The unfolding and embodiment of awareness within the body is sporadic and at times seemingly random. Sometimes there is sequentialness but most often this unfolding seems to be indeterminate and completely free. The different energy centers are opened from within by the infused energy of light.

The sphere of sexuality is opened within awareness and infused through awareness becoming light, becoming the soma of light. The sphere of Eros is subsumed within the heart essence of pure ontological love. Eros and ontological love become viscous light, forming the heart drops of Dharmakaya. Amrita flows throughout the body as the body of light is forming and informing human experience of everything and anything.

\section{Embodiment of Light}

The instinctive energies are subsumed into the embodiment of light. The psyche-somatic union becomes the luminous vase of luminous human awareness as gnosis. The experience of unborn and undying awareness springs forth in a sustained and sustaining manner. The sense of ongoing continuity of Being remains within the context of appearing and disappearing and reappearing.

The three dimensions of human experience as Nirmanakaya, Sambogakaya and Dharmakaya are experienced simultaneously as Savabhavikaya as one view, one simultaneous multidimensional view. The sound $\mathrm{Mu}$ can be a summation of this invocation. The primordial 
foundational anxiety of deprivation and annihilation are dissolved by light, infused by the light, metabolized by the light of awareness field.

\section{Bliss Overcomes Suffering}

There is the great tantric understanding is that Bliss overcomes suffering. Bliss arises as the ordinary person experiences the experience of non- duality within their embodiment. Bliss is a function of the integration of Eros into the field of pervasive light. The very embodiment of the light brings forth the luminous sense of embodiment of light and the infusion of luminous being-ness with the embodiment of the instinctive energy centers. Becoming infused with the light brings forth states of bliss and equanimity. The heart drops of the Dharmakaya are openings within the innermost Heart Center so that within their opening there is release of liquid like states of light, viscous light that is both luminous and blissful which permeate everything and anything. Within in this experience there is the ongoing continuity of awareness that unfolds through life circumstance and beyond; beyond death itself. Unborn and undying timeless awareness is the essential nature of awareness.

Experiencing the Inner Guru in Yourself and Experiencing the Inner Guru in Others: the Tantric practice of Guru Yoga

Guru yoga is the praxis of experiencing the sublime dimension of the Guru within your own embodiment of awareness and experiencing the sublime dimension of the Guru in Others. This is the most essential practice of Tantra. To experience the profound light of awareness within your own embodiment and the embodiment of others brings forth an intense resonance of light and energy between yourself and others. This is the most direct experience of duality within non- duality and nonduality within duality. The guru is the self-manifestation of awareness, 
self- manifestation of light. The guru is logos. The Guru is the grace bestowing principle of awareness.

This experience of the primordial guru awakens naturally the indivisibleness of the light of awareness. As the Dakini said to the great Dzogchen Master Dudjom Lingpa in the late 19th century: "You and I are Indivisible." This indivisibleness can also be felt with those whom we love and even those we hate. This indivisibleness can be experienced with others who are physically far away from us and so non- localness does not limit our experience of the divine guru dimension. This indivisibleness can be felt even after death with those whom we love. This felt sense of the presence of the inner guru in not a function of our mind alone, rather the felt sense of a function of our own innermost awareness, its infinite horizons and vast multidimensionality.

Of course to experience the guru within us and within others gives us the gift of equal vision and equality consciousness. What is in you is also in me. This experience is not a function of belief but the function of perception, of knowingness.

The Tantric Practice of the Embodiment of the Archetypal Dakini

The practice of invoking and embodying the feminine anima mystic dimension of the Dakini is the praxis that opens and deepens our experience of psyche and direct perception, of gnosis, jnana. The tantric practice of the shamanistic invocation both within ourselves and situations brings forth clarity and luminous energy. This capacity is a function of being able to access timeless awareness in time, and from within timeless awareness bringing forth the divine light of awareness into time. This is also the practice of absolute compassion wherein from timeless awareness we bring forth and extend forth the light of compassion within our self and within others. From this position of the 
fourth time, we can extend into a person's present moment, we can extend into their past and we can extend into their future. We can have the same practice for context such as a city, or situation.

The archetypal dimension of human existence is central to the understanding the magical power of Tantra. What is also central is this understanding is that the feminine dimension which is ultimately direct knowingness of awareness is not the same knowingness of mind alone.

The knowing of awareness knows Being and the knowing of mind knows forms. In union the simultaneous knowing of awareness and mind we can directly know the Being-ness of beings and the Being-ness of Being itself. The union of mind and awareness knows form and formlessness simultaneously. The union of mind and awareness knows beings and Being simultaneously. The union of mind and awareness knows Being within beings.

Tantric Distortions of Equality Consciousness In Light of Theocracy Equality Consciousness

Tantra is not supernatural event but the natural unfolding of humanness as the embodiment of light, as the somatic psyche embodiment of light. The essence of all Tantra is the experience of equality consciousness. The equality of all phenomena and all persons is self-liberating experience. Equality consciousness is the secret of selfliberation for all human beings. True realization is equality consciousness of everything and everyone.

\section{Co-Emergent}

Tantra is a co emergent event. Out of sublime resonance the presence of awareness manifests between two or more people. The light and energy of light resonates to the light of the other and within the other. This is the essence of the awakening of awareness and the deepening and 
unfolding of luminous awareness between and within people and within the world itself.

\section{Co Emergent Destroys Asymmetrical Views}

Tantra as a co emergent event radically destroys the asymmetrical view of relational life, and the asymmetrical view of spiritual life. There is no hierarchy in Tantra. Tantra is in the truest and deepest sense antihierarchical. Tantra has the implicit quality of anarchy. There is no above or below, there is no better or best. There is only one taste. There is ultimately only one Being manifesting being within and as all beings. The Being-ness of Being is manifesting within the vast resonance of the field of awareness!

\section{Purity of Phenomena}

The essence of all phenomena is purity. This is the purity of the Beingness of Being no matter what the form of the being. Tantra radically takes us beyond the pairs of opposites, beyond right and wrong, beyond good and evil, beyond better and best and even beyond truth or falsity. Everything and everyone is equal in status and in the actuality of living in divinity as divinity. The guru is within everyone and within every being. The guru is the self- revelation of awareness manifesting itself as us. The guru is the logos. All appearance are divine. The Divinity of Appearance is the heart of Tantra.

\section{Guru is not a Person}

Tantra cannot be institutionalized. Tantra cannot be stratified. In Tantra the guru is the light of our own awareness. The guru is the light of our own awareness revealing itself to us and through the very circumstances of our life. The primordial guru cannot be institutionalized as person. The primordial guru is primordial awareness, ground awareness. The primordial guru is not a person. 
The relentless attempts at the institutionalization of Tantra do not reflect the essential nature of Tantra. The attempted institutionalization of Tantra can neutralizes and minimize the liberating power of Tantra. The power of the self- revelation of awareness is the primordial guru. The power of the guru is within everyone and beyond everyone. The primordial guru is not a organizational structure as some would think, a theocratic structure.

The ecclesiastical and clerical attempts to institutionalize Tantra can veil the nature of Tantra. There is no hierarchy within gnosis, no hierarchy within direct perception. There is no social or cultural hierarchy surrounding the nature of the primordial guru. The guru cannot become an institution, a corporation. The guru is not a church. The guru is the light of our very own awareness revealing itself to us through our life and life circumstance. The guru is timeless awareness manifesting in time and space. The guru is not royalty.

\section{Buddha Mind Becomes Buddha Man}

When Tantra is institutionalized, the very nature of the Guru is seemingly institutionalized. This is illusionary. The guru rather than being the very nature of inner most awareness becomes externalized as Person as Guru. Buddha mind becomes Buddha Man. This is the anthropomorphism of the ontological. The Guru is not a personal psychology.

Tantra is not a state secret. Tantra is the light of awareness illuminating everything and everyone in time and through time. Timeless awareness illuminates the trans-lucidity of human experience, both personal and cultural. In Tantra all secrets are revealed in time. Secrecy obscures the power and presence of luminous Tantra. The trans-lucidity of awareness in time destroys the secrecy of traditions. 


\section{The Guru as Authoritarian Theocratic Personality}

Clerical and monastic concerns attempt the institutionalization of Tantra and the institutionalization of guru. The realm of the guru becomes secret and the actuality of the guru becomes distorted by the authoritarian structures and authoritarian personal status. The guru is projected outside of our own innermost self- awareness into the Divine Other, the Holy Authority. There is this projection of divinity of the guru's presence into a person as Divine authority. Divine Authority easily becomes the authoritarian personality. This happen in most eastern and western religious traditions. The divine hierarchy is created and sustained by devotion and financial generosity to the person perceived as guru. This is a socialization and personalization of ontology.

The guru becomes viewed as person and personality outside of our own innermost self. The guru is not a person. We shift from our innermost awareness to having a fan- like devotion to the holy other. Then we are more often than not, asked or required to obey the divine will and divine infallible authority of this holy other person. We move from co-emergent experience to personal dependency on the newly found infallibility of this person of authority. This is of course the drama of the authoritarian personality. This is a well research theme in social psychology. This ever occurring authoritarian event is the moment of the joining of spirituality and royal governance.

An Important Historical Unfoldment in Tibetan Buddhism

A brief look into the historical unfoldment of Tibetan Buddhism.

In Tibet during the 8th century the village and shamanistic based Nyingma tradition brought forth the Guhyagarbha Tantra. In and through this most wonderful truly Tibetan Tantra the divinity of everyone and everything became unveiled. A truly pantheistic view emanated into 
the Vajra jnana tradition. Of course this Tantra was and is challenged by the new translation lineages as being only Tibetan in origin and not reflective of the historical Indian Buddhist Sanskrit traditions which existed in India and came to Tibet in the 11 th century. In fact this Guhyagarbha Tantra was an unfoldment of the wheel of dharma far beyond early Indian Buddhism with its Sanskrit alliance. The Guhyagarbha Tantra went far beyond the third unfolding of the wheel of dharma which was the Uttara Tantra of the 4th century. The 8th century Guhyagarbha Tantra brings pantheism into foreground in the Nyingma tradition.

The Uttara Tantra brought forth the magnificence and positive understanding of the wisdom mind, the Buddha mind being the cosmological source of everything and anything. This Tantra also emphasized the Tathagatagarbha tradition of Indian Buddhism. This was a great step and leap in Buddhism as there was at last the understanding of wisdom being the cosmological source of everything and anything. The understanding of the Uttara Tantra was that the Buddha nature is within everyone in seed (garbha) form. And that everyone has this seed of wisdom awareness and with practice and understanding the Buddha nature could become fully experienced by everyone. This is the Tarthagatagarbha. This Indian Buddhist understanding was and is the understanding of the new translation schools of Tibetan Buddhism of the 11 th centuries until the present time. This is the sustained view of the seed of wisdom becoming a Buddha was in everyone and this view remains in central place of the new translation traditions such as the Kagyu karma and Kagyu Drikung lineages.

The Tarthagatagarbha is the seed in the disciple that must come into fruition through the theocratic formulation of the guru as the Buddha personified as the Lama person as guru. The seed frame still maintains 
central understanding in the theocratic and corresponding asymmetrical framing of spiritual experience and growth within theocratic culture.

\section{Guhyagarbha Tantra}

This Uttara Tantra view is more contracted and limited then the vast open view of the Nyingma tradition as expressed in the Guhyagarbha Tantra. The profound shift in view and path is the understanding that Buddha nature is not simply a seed within all sentient beings, but is the very nature of all sentient beings just as they are. Divinity is complete within everyone and everything. The Secret Essence Tantra goes beyond the theme of the Tarthagatagarbha which is the understanding that all beings have the innate potential to become Buddhas. The theme of the Tathgatagarbha is dramatically extended to embrace a view that everything is already the Buddha.

This Secret Essence Tantra (Guhyagarbha) as Douglass Duckworth points out is a most important shift from the view of Buddha nature as Tathagatagarbha which is the universal potential for awakening, to the understanding of the Secret Nature Tantra which is that everything and everyone is the Buddha nature now. This is a radical unfolding of the movement towards immanence of Divinity rather than the transcendence of Divinity. This is the profound understanding of the Divinity of appearance of everything and anything. This is pantheism.

\section{Completeness}

Moreover, this liberating view that everyone is the Buddha nature now, directly influences the understanding of the nature of the guru being in everyone. The guru is the self-revelation of primordial awareness as Buddha mind in everyone. Thus the power of the inner guru is clearly understood and recognized as central to the unfolding of the path of selfliberation. The power of the inner guru and the manifestation of the guru 
in our life takes us beyond the theocratic excess of the guru being personalized as the perfect omniscient Lama as a Buddha Man. The guru is not a person, it is the self- revealing power in each of us.

\section{Dynamic Hermeneutic Unfolding}

There is a way to hold simultaneously the Uttara Tantra and the Guhyagarbha Tantra in the dynamic hermeneutic unfolding of the truth of experience. The Guhyagarbha Tantra reveals the immanence of Divinity as everything and as everyone. In the context of the Guhyagarbha Tantra, the Uttara Tantra brings forth the understanding of the necessity to experience the truth of the actuality of the immanence of Divinity for self- liberation to be experienced. All experience and all appearance is Divine and self- liberation is the direct experience of the actuality of pervasive Divinity within one's self as one's self and in others as the self of others.

Theocratic Thrills

Theocracy is the process of spirituality being joined with royalty. This process is the process of governance being spiritualized. Governance and the bestowal of grace become married. This is a political joining of governance and spirituality. This form of understanding unfolded within monastic culture and remains within Buddhist culture. To live in monastic culture is to live within the theocratic frame. Lamanism is the theocratic cultural frame of Tibetan Buddhism of the new translation epoch. This socio- religious frame is lived existentially beyond equality consciousness. The socio religious frame is not Tantra but theocracy.

Dzogchen Challenge by Longchenpa

Longchenpa in his great Dzogchen text Words and Meaning describes some of the natural distortions of Tantra within the context of Tibetan Buddhism. One such distortion to use Longchenpa's words is a neurotic 
preoccupation with the sexual dimensions of Tantra and the search for the perfect consort. There is also a distortion through the emphasis of ritual sexuality as described in the Yogini Tantras. Longchenpa described sexual practice becoming obsessional and fixated and missing the unbound open and natural focus of Dzogchen.

Longchenpa describes the sexual preoccupation as neurotic distortion. Sexuality for some became the hyper focus of the path of self-liberation. This singular fixation destroys the open Dzogchen view of everything and any circumstance as the path of self-liberation. There also arises a denial and a state of secrecy about sexuality playing such an important part in the lives of tantric practitioners as well as in the lives of monks living in monasteries. Many great yogic Buddhist masters have spoken about the over emphasis on sexuality as expressed in the yogini Tantras. Atisha, Longchenpa, Tsongkhapa and Mirpham were some of the masters who challenged the distorted tantric fixated-ness on sexual ritual as the singular focus of self-liberation.

Lama as Buddha Man

Most importantly the theocratic realm of the Kagyu Karma and Kagyu Drikung lineages explicitly taught that the lama should be considered to be the Buddha, a Buddha person, Buddha man. So the Buddha person is perfect in mind, perfect in actions, perfect in omniscience, perfect in intentionality and perfect in infallibility of judgement. The person as the guru is now seen as all knowing. This view is not the democratic view of equality consciousness and co-emergent path of Tantra. This is the view of theocratic and intrinsically hierarchical framing of social experience. This is not the opened ended view of equality consciousness being both the source and the result of self-liberation. They see the seed of potentiality in everyone but not the actuality of completeness just "as it is." 
This is not the 8th century Nyingma village shamanistic experience of Guhyagarbha Tantric admonition to see the Buddha in everyone and everything and in experiencing divinity in everyone and everything. This is not the understanding about the divinity of all experience and the divinity of all appearance. This is an extreme externalization of seeing the lama alone as the guru and as the Buddha. This is the externalization of the inner guru and minimization of inner guru as our own inner most awareness.

Personification of Archetypal Dimension

This seeing the lama as the Buddha is a personification of the archetypal dimension that is within everyone. This personification may be somewhat helpful in the mirroring recognition that this power of self revelation is in you.

However, this power of mirroring recognition easily succumbs to the authoritarian and omnipotent view of infallibility of Buddha as person. In fact Buddha is not a person at all but the realm of primordial awareness creating and illuminating everything as light. This is the anthropomorphism of this cosmological function of light of revelation. It is true that person embodies this dimension of luminous light. But this embodiment is not an institutional event. This personal event of selfillumination is far beyond institutionalization.

The Buddha as a Person is Actually Dead!

There was a person who lived in the 5th century and taught the path of the noble truths and he was called the Buddha. He also had the names of Gautama and Shakyamuni. He died and his death caused great deal of suffering and loss for his many followers. His loss was a great rupture and through this rupture in hermeneutic time, there unfolded the understanding of Buddha nature being primordial wisdom manifesting 
everything and anything. Buddha was no longer a signifier of person but the signifier of the nature of primordial awareness itself. One more time! The Buddha was no longer a signifier of a person but a signifier of the nature of primordial ground awareness.

The Buddha mind became a signifier of ontological dimension of existence. The Buddha mind become ontological source and cosmological source. To say a human person is the Buddha is a symbolic and metaphorical misattribution. In fact a person is not the source of existence of the universe.

When we personify a person as Buddha within the theocratic institutional context there arises an unhappy phenomena that take naturally takes place. And that is whatever he says, whatever he thinks, whatever request he makes, he does this as the Buddha. In truth he is not the Buddha, the Buddha died in the 5th century BC. To think this way is grandiose at best and at worst a comedia.

Admonition: Do not challenge the Buddha-Lama or Buddha Man

A result of this theocratic view the result is that the ordinary person should not question the Buddha Lama, the Buddha Man, the god man. The only function is to serve the lama and please the lama, to serve the Buddha as lama. Whatever the lama does should be seen as perfect since he is primordial awareness personified. The lama is thought to be beyond good and evil. So the lama should be thought of as godlike or a godman view. A Christian might say or think Buddha man is Christ like. Or perhaps organizationally a Christian person may think the Buddha lama is Pope like. Of course the belief in Papal Infallibility in speech and action and intention is a sublime expression of the theocratic illusion. The Buddha lama is the living union of spirituality and governance. Politically there is the socio-political induced requirement for deference. To 
challenge the Lama Buddha posture and Lama Buddha words and actions is unholy arrogance.

The Sin of Sins

Questioning or challenging the lama is considered a terrible sin...the worst of worst. And so for religion when all else fails there is the falling back on the invocation of the hell realms. Some religious traditions when challenged like to use the burning at the stake method (Christian favorite), and some in a more imaginary mood use the threat of endless hell realms punishment method (Buddhist favorite). A Hindu favorite seems to be that all your wealth will disappear and then you die and come back as a hungry rat.

Self- illumination

Of course the guru is unfolding process of self- revelation of the selfillumination of primordial luminous awareness. The guru reveals the nature of existence as luminous openness. This process of ontological self-revelation is usurped by institutionalization of personal Buddhahood. This is a grandiose power framing of guru. This view presents the guru as king and as spiritual royalty. In the Kagyu traditions there is very little emphasis on reality of the inner guru. The primary and singular focus is on the external form of the lama being the guru as a Buddha man. As the Kagyu Drikung lama says: 'See me as the Buddha. See me as Buddha man'. If the understanding was to see every person as the Buddha and not simply the Lama, then pantheism would flourish. When the understanding is that Buddha is not a person, the Buddha mind signifies a metaphorical reference to primordial awareness manifesting everything and anything as luminous phenomena.

The invocation of Buddhahood as the lama is a rhetorical injunction and these kind of rhetorical instructions create ethical problems as to the 
ethics of the drama of sexual Tantra in the context of sexuality between guru as Buddha Man and the dependent devotee.

The Problem of Consensual-ness between Ordinary Person and a Buddha Man Person

We will now briefly explore the drama of consensual consenting to the divine Buddha Man. Once, I heard a young women described how she did not know what she would do if the lama asked her to have sex with him. She said he was her guru. She said he was Buddha personified in her life. She continued to feel that her job was to please him and the lama only has her welfare in mind. Yet she do not want to have sex with him. As she said, "What am I to do or not do? I have turned my self- agency over to the authority of my teacher as Buddha."

Here is the presentation of masochism, the kind of masochism that is pervasive in religious life and in monastic life in particular. I have given my self- agency over to the Buddha Man in order to experience the grace of the Guru. The guru as person now becomes the external source and external super-agency of the grace of the guru. This is the theocratic formulation of the religious and a monastic view of Guru as Buddha Man.

Theocracy is not Democracy

Theocracy is not democracy. In theocracy there is the unhappy fusion of royalty and spirituality. There is the fusion of governance and spiritual authority. The theocratic view imposes both an implicit and explicit asymmetrical view of leader and follower, teacher and student, guru and disciple. This is not the mutual co-emergent path of the Tantric path. The traditional saying the Guru is the means in this limiting context means both being and living in obedience to the guru. The process of selfrevelation shifts to the revelation of the truth of experience by the Buddha Man. The truth of Being becomes externalized. The traditional saying the 
Guru is the means in the truest sense is the unfolding luminous experience of the guru as the essence of our own awareness.

\section{Sacred Secrecy}

Secrecy is considered an aspect of Vajrajnana Tibetan Buddhism. Tibetan Buddhist often has secret practices .There is an ontological secrecy in that the self-manifestation of the divinity of all experience is obvious and yet this is naturally secret and hidden even though the actual is made completely explicit. Those who have eyes to see can see, and those who have ears to hear can hear.

There is another secrecy. This is a political secrecy that is protection for the lama as Buddha man and protecting the fantasy of omnipotence and infallibility. Lamas have described how Tantric sexuality can take place between students and teachers, between devotee and guru. This Tantric drama is often protected as a secret practices. These practices may work very well in Tibetan culture but in contemporary American culture with the unstoppable growing self -liberation of women, this asymmetrical sexual drama is tragic and culturally stupid.

Tantra and Equality Consciousness

Seeing or believing that the lama is the all good total divine Buddha is a distortion that prevents and veils the truth of experience. Tantra is the practice of equality consciousness. The experience of equality consciousness is the complete essence of Tantra. In the configurations of Lamanism, there is an asymmetric theocratic drama. Theocracy is the complete opposite of equality consciousness and theocracy is domination, a form of royal spiritual political domination.

In Washington, DC a few years ago the Dali Lama during the week long Kalachakra empowerment spent one lecture speaking about and challenging Lamanism and the power of Lamanism as disabling to 
Tibetan Buddhism in contemporary society. His talk was most amazing in his seriousness and his concern about continued and pervasive Lamanism and its limitations on the unfolding of Tibetan Buddhism's continued existence into this century and beyond.

When there are distortions of equality consciousness between teacher and student, guru and devotee, there is the distortion of the guru as protector. There is a distortion of the great compassion for devoted and dependent people. This is foundationally true in the Vajrajnana as the great compassion is great protection. It there is no protection how can there is be great compassion? Compassion without actual protection is a comedia.

The great compassion is the action of actual protection. Without the action of protection, the great compassion becomes a big wish, such as I wish you well. Without action of protection, the great compassion becomes like the wish for a happy birthday. The great compassion becomes good manners.

\section{Conclusion}

In the mountain high kingdom of Tibet the medieval asymmetrical domination of Lamanism fit the epoch and the place. The theocratic royal patriarchal society had both spiritual and political domination of everyone. In coming to America the asymmetrical-ness of Lamanism and its patriarchal framing has been slowly deconstructed step by step.

As Carl Jung described early in the 20th century, the Piscean age is coming to an end. The Piscean age of patriarchal and theocratic domination of spirituality and royal governance being co-joined is coming to a final end. With the unfolding of this new epoch both the role of women and the role of the inner guru is becoming liberated. The explicit role of the inner guru challenges the theocratic view of the Guru. 
During this current moment in time, the existential metaphor of Trumpism and the existential metaphor of million women February 2017 is being played out all over the world, including within contemporary Tibetan monasteries. This is a cosmological event of self-liberation. This is also the time for the liberation of Tibetan Buddhism from its theocratic illness. Longchenpa would love this moment! 


\section{Bibliography}

Davidson,Ronald.2002. Indian Esoteric Buddhism; A Social History of The Tantric Movement. New York: Columbia University Press.

Dudjom Lingpa.Buddhahood Without Meditation,Translated by Richard Barron and Susanne Fairelough. Junction City,Ca;Padma publishing.2006

Dyczkowski,Mark s.g.1987. The Canon Of The Saivagama and Kubjika Tantras Of The Western Kaula Tradition. Albany;State University of New York.

Gray,David. 2007. The Chakrasamvara Yantra,New York; American Institute of Buddhist Studies/Columbia university press

Heidegger,M.1999. Contributions To Philosophy .P.Emad and K.Maly, Transl. Bloomington; Indiana University Press.

Henry,M.1973. The Essence Of Manifestation, The Haque; Nijhoff.

Marion,G.(2002a). Being Given: Toward A Phenomenology of Givenness. Stanford,Ca:Standford University Press.

Merleau Ponty, The Visible and The Invisible. Translated by Alphonso Lingis. Evanston,ill.;North Western University Press, 1968.

Merleau Ponty. Phenomenology of Perception. Translated by Colin Smith.London; Routledge and Kegan Paul.1981

Romano,C.(2009). Event and World. Bronx,N.Y; Fordham university Press.

Winnicott,D.W. 1971.Playing and Reality.New York: Basic Books. 